\title{
Transseptal implantation of HighLife self-expandable mitral valve in a patient with severe secondary mitral regurgitation and heart failure
}

\author{
Wojciech Wojakowski', Grzegorz Smolka', Nicolo Piazza², Radosław Gocoł³, Damian Hudziak, Marek Jędrzejek1, \\ Piotr Pysz ${ }^{1}$
}

'Department of Cardiology and Structural Heart Diseases, Medical University of Silesia, Katowice, Poland

2Division of Cardiology, Department of Medicine, McGill University Health Centre, Faculty of Medicine, McGill University, Montreal, Quebec, Canada

${ }^{3}$ Department of Cardiac Surgery, Department of Cardiac Surgery, Medical University of Silesia, Katowice, Poland

\author{
Correspondence to: \\ Prof. Wojciech Wojakowski, \\ $\mathrm{MD}, \mathrm{PhD}$, \\ Division of Cardiology and \\ Structural Heart Diseases, \\ Medical University of \\ Silesia, \\ Ziołowa 45, 40-635 \\ Katowice, Poland, \\ phone: +48 604188669 \\ e-mail: \\ wwojakowski@sum.edu.pl \\ Copyright by the \\ Author(s), 2021 \\ Kardiol Pol. 2021; \\ 79 (6): 708-709; \\ DOI: 10.33963/KP.15960 \\ Received: \\ March 1, 2021 \\ Revision accepted: \\ April 11, 2021 \\ Published online: \\ April 16, 2021
}

The report presents the initial Polish experience with trans-septal transcatheter mitral valve implantation using the HighLife valve, specifically developed, for a patient with moderate-severe to severe functional mitral regurgitation. HighLife is a trans-septal self-expandable valve consisting of a nitinol frame with bovine pericardial leaflets and a post-implant mitral annular diameter of $28 \mathrm{~mm}$. The patient was a 70-year-old male with New York Heart Association (NYHA) III class heart failure. He had a history of coronary artery disease (16 years after coronary artery bypass grafting [CABG]), atrial fibrillation, pacemaker implantation, hypertension, diabetes mellitus, and obesity (body mass index [BMI], $35 \mathrm{~kg} / \mathrm{m}^{2}$ ). Echocardiography showed left ventricular (LV) enlargement (end-diastolic diameter [EDD], $70 \mathrm{~mm}$, end-diastolic volume [EDV], $211 \mathrm{ml}$ ) with mildly depressed LV ejection fraction (52\%) and severe functional mitral regurgitation (Supplementary material, Figure S1). The Heart Team deemed the patient inoperable. Preprocedural multislice computed tomography showed a proper size of the mitral annulus and a low risk of LV outflow tract obstruction. The procedure was performed under general anaesthesia. The procedural steps consisted of the retrograde crossing of the aortic valve and introducing the loop placement catheter below the aortic valve and creating a loop with a guidewire encircling the chordae tendineae. Using the ring delivery catheter in the LV the subannular ring was advanced and closed after confirmation of proper positioning. The ring formed a landing zone for the valve. The interatrial septum was punctured and balloon septostomy with
$10 \mathrm{~mm}$ balloon performed. A stiff Lunderquist wire was placed across the interatrial septum and the transeptal valve delivery system introduced into the LV. The LV portion of the valve was gradually deployed within the subannular ring, the valve is pulled against the ring, pushing the ring against the native mitral annulus, then the atrial portion is released (Figure 1). The transesophageal echocardiograpy (TEE) confirmed the proper function of the valve with no mitral regurgitation and no paravalvular regurgitation (Supplementary material, Figure S2). The arterial access site was closed with Manta $18 \mathrm{~F}$ device and venous access with an " 8 " suture. The patient was extubated in the hybrid room and ambulated the next day. He initially reported alleviation of heart failure symptoms, but at 1 month FU presented overt signs of right ventricular decompensation. TEE visualized significant right to left shunt across persistent iatrogenic atrial septal defect (ASD; oblong-shaped with max. dimension of $2.95 \mathrm{~cm}$ and an area of $2.15 \mathrm{~cm}^{2}$ ) which was subsequently closed using the ASD Amplatzer plug (Supplementary material, Figure S3-S4). Further course was uneventful and the patient remains stable in NYHA class II at 5 months post-TMVR. This case is one of the first 15 transseptal HighLife valves implanted worldwide. Previous clinical data showed the feasibility and safety of the earlier transapical version of this device [1]. The possibility of a transseptal approach is the advantage of this technology and as a less invasive technique, it is a goal of the progress of the transcatheter mitral valve implantation field [2]. The key features of the HighLife valve is a stable landing zone formed by the subannular ring 


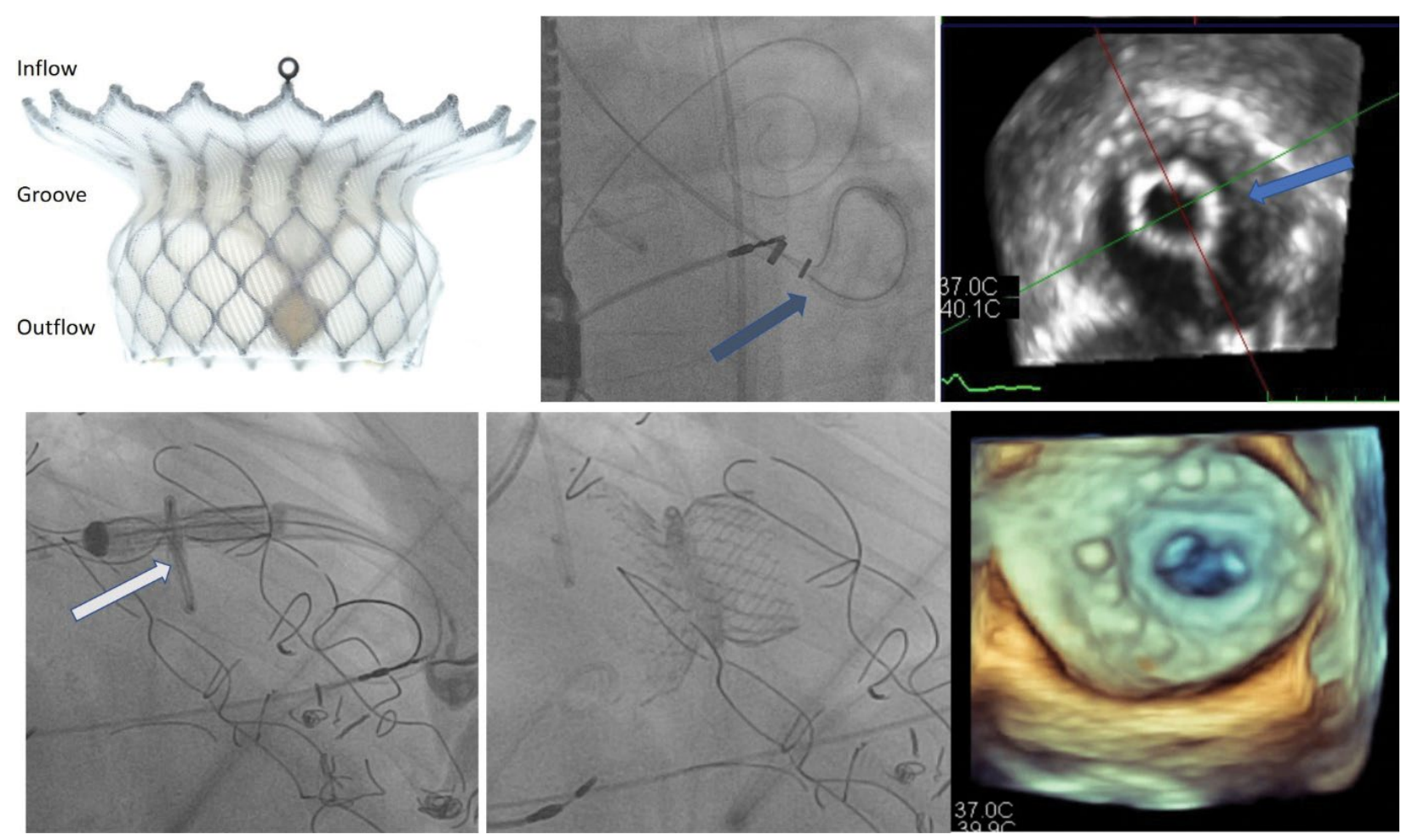

Figure 1. Fluoroscopy and transoesophageal echocardiography depicting the steps of High Life valve implantation. A. $28 \mathrm{~mm}$ HighLife self-expandable valve. B. Fluoroscopic image of loop placement catheter across the aortic valve with a closed ring encircling the mitral valve chords. C. Echocardiographic short-axis view showing the ring (arrow) and loop placement catheter. D. Fluoroscopic view of the valve in the capsule positioned to match the groove with the subvalvular ring. E. Deployed valve. F. 3D atrial view in transoesophageal imaging of the valve

controlled deployment and fully percutaneous access. The most important anatomic requirements currently are not over-large mitral annulus and no evidence of LV outflow tract obstruction on pre-procedure computed tomography review and adequate arterial vascular access.

\section{Supplementary material}

Supplementary material is available at https://journals. viamedica.pl/kardiologia_polska.

\section{Article information}

Conflict of interest: The authors are investigators in the HighLife clinical trial.

Open access: This article is available in open access under Creative Common Attribution-Non-Commercial-No Derivatives 4.0 International (CC BY-NC-ND 4.0) license, allowing to download articles and share them with others as long as they credit the authors and the publisher, but without permission to change them in any way or use them commercially. For commercial use, please contact the journal office at kardiologiapolska@ptkardio.pl.

How to cite: Wojakowski W, Smolka G, Piazza N, et al. Transseptal implantation of HighLife self-expandable mitral valve in a patient with severe secondary mitral regurgitation and heart failure. Kardiol Pol. 2021; 79(6): 708-709, doi: 10.33963/KP.15960.

\section{REFERENCES}

1. Barbanti M, Piazza N, Mangiafico S, et al. Transcatheter mitral valve implantation using the HighLife system. JACC Cardiovasc Interv. 2017; 10(16): 1662-1670, doi: 10.1016/j.jcin.2017.06.046, indexed in Pubmed: 28838477.

2. Overtchouk P, Piazza N, Granada J, et al. Advances in transcatheter mitral and tricuspid therapies. BMC Cardiovasc Disord. 2020; 20(1): 1, doi: 10.1186/s12872-019-01312-3, indexed in Pubmed: 31910809. 